\title{
Clinical, neuroimaging, biochemical, and genetic features in six Chinese patients with Adrenomyeloneuropathy
}

\author{
Jie $\mathrm{Li}^{1+}$, Hongfen Wang ${ }^{1 \dagger}$, Zizi He ${ }^{1}$, Xiangqing Wang ${ }^{1}$, Jing Tang ${ }^{2}$ and Dehui Huang ${ }^{{ }^{*}}$
}

\begin{abstract}
Background: Adrenoleukodystrophy is a rare neurogenetic disease, AMN is the most common adult phenotype, such patients in China have not gotten enough attention. This article aims to study the features of AMN in Chinese patients and expand the gene spectrum of Chinese X-linked adrenoleukodystrophy (X-ALD) patients.

Methods: We applied clinical analysis, radiology, plasma levels of very long chain fatty acids (VLCFA) and genetic analysis to test the 6 Chinese AMN patients.

Results: All 6 patients are men. Ages of neurological symptom onset are distributed between 21 and 38. Sexual dysfunction occurred in 5 of 6 patients. Three patients had positive family history. Five patients had Addison's disease. Four patients were diagnosed as pure AMN, while the other two patients were with cerebral involvement. Four patients had abnormalities of nerve conduction studies. There were four patients with central conduction defects in somatosensory evoked potential tests. All 6 patients were found diffuse cord atrophy in spinal MRI. Brain MRI showed abnormal signals in 2 of the 6 tested patients, which indicated the clinical phenotypes. Plasma levels of VLCFA, as well as C24:0/C22:0 and C26:0/C22:0 ratios were elevated in 5 tested patients. Five different ABCD1 mutations were identified in 5 tested patients, one of which was a de novo mutation, and the other four have been reported previously.

Conclusion: This research described the clinical, neuroimaging, biochemical, and genetic sides of Chinese AMN patients. A de novo mutation in the ABCD1 gene sequence was identified. Emotional trauma may trigger or aggravate the development of cerebral demyelination in AMN patients. Regular evaluation of brain MRI is important for AMN patients, especially for 'pure AMN' patients. When encountering patients with 'myeloneuropathy-only', neurologists should not ignore the tests of VLCFA or/and the ABCD1 gene.
\end{abstract}

Keywords: Adrenomyeloneuropathy, Addison disease, Spastic paraparesis, Very long chain fatty acid, ABCD1

\section{Background}

$\mathrm{X}$-linked adrenoleukodystrophy (OMIM\# 300100) is an inherited disorder of peroxisomal metabolism, typically presented with impaired degradation of saturated VLCFA [1, 2]. Childhood cerebral ALD and AMN are the two most common forms of ALD, while these two phenotypes have different clinical and pathological characteristics. Generally, cerebral ALD is early onset and renders a poor prognosis, with a representative feature

\footnotetext{
* Correspondence: huangdehui11@foxmail.com

${ }^{\dagger} \mathrm{Jie}$ Li and Hongfen Wang contributed equally to this work.

'Department of Neurology, Chinese PLA General Hospital, Fuxing Road 28,

Haidian District, Beijing 100853, People's Republic of China

Full list of author information is available at the end of the article
}

of rapidly progressive neuroinflammatory of cerebral demyelination. Known as a form of X-ALD, neurological symptoms of $\mathrm{AMN}$, in general, occur from the ages of 20 to 50 and manifests as a chronic progressive paraparesis, accompanied with sensory and sphincter disturbances [3, 4]. It is worth noting that the neuropathology of $A M N$ is different from the inflammatory cerebral form [5]. The fundermental neuropathological abnormality of AMN is a dying-back axonal degeneration. In this regard, it has a great impact to the cervical fasciculus gracilis and lumbar corticospinal tracts [5, 6]. Furthermore, the corticospinal tract in the posterior limbs of the internal capsule is also involved and may lead to secondary

(C) The Author(s). 2019 Open Access This article is distributed under the terms of the Creative Commons Attribution 4.0 International License (http://creativecommons.org/licenses/by/4.0/), which permits unrestricted use, distribution, and 
corticospinal tract degeneration in the midbrain, pons, medulla, and spinal cord [5, 7]. The peripheral nerves damage can also occur in AMN patients, but peripheral nerve involvement is often overshadowed by prominent spinal cord symptoms $[8,9]$. According to whether there is any evidence of cerebral white matter lesions, AMN can further divided into 'pure AMN' and 'AMN-cerebral' forms. With a mean follow-up of 10 years, study showed that nearly $19 \%$ of patients with pure AMN developed into cerebral demyelination [10]. However, this threat can diminish significantly with age especially after 45 [11]. Due to the heterogeneity of clinical manifestations, it is difficult to diagnose AMN earlier. The clinical features of Chinese AMN patients have not been systematically evaluated until now. Therefore, the present research focuses on surveying the features of clinical, biochemical, neuroimaging and genetic information with Chinese AMN patients.

\section{Methods}

Our group reviewed and investigated Chinese AMN patients followed at Chinese PLA General Hospital, from August 2012 to January 2018. Patients meeting the following two inclusion criteria were enrolled according to case histories: (a) Adult onset with spastic paraparesis, (b) cases with mutations of the $\mathrm{ABCD} 1$ gene or/and increased plasma levels of VLCFA, particularly the proportions of C24:0/C22:0 and C26:0/C22:0. With the basis of the above two standards, the study selected 6 AMN patients.

Clinical information were screened out case histories, which included age of neurological symptoms onset, family history, onset time of cognitive impairment, motor function, sensory disturbance, plantar reflex and other related signs, for instance, sexual dysfunction, urine disorder, bald and increased skin pigmentation. Plasma adrenocorticotropic hormone (ACTH) (normal range: 1.1-278.0 pmol/L) was tested in all six patients. Adrenal insufficiency was defined according to the baseline of plasma ACTH level at 08: 00 am greater than $10.12 \mathrm{pmol} / \mathrm{L}$. Additionally, we adopted electrophysiological and radiological studies methods to assess damage to the nervous system. We used standardized techniques at room temperature when conducting electrophysiological studies. Five of six patients underwent nerve conduction studies. Furthermore, four of six patients also performed somatosensory evoked potential tests. Brain and spinal MRI scans were performed in all six patients. All patients underwent $1.5 \mathrm{~T}$ magnetic resonance imaging, of which 2 patients underwent MRI enhanced scan. Conventional SE sequence included T1-weighted images; T2weighted images; Diffusion-weighted images and T2-fluidattenuated inversion-recovery sequence. Gadolinium spray was used as the enhancer, the neuroradiologist of Jing Tang reviewed all neuroimaging results. VLCFA were detected by gas chromatography - mass spectrometry in five of six patients. The ABCD1 gene mutations characterized by a custom-made target exome capture panel (MyGenostics, Beijing, China) were analyzed in five of six patients (patient 3 refused to perform genetic test for economic reasons).

\section{Results}

\section{Clinical characteristics}

Table 1 lists the clinical characteristics of the six AMN patients. Median age at onset of neurological symptoms was 29.8 years and ranged $21-38$ years. Duration of follow-up from onset ranged between 47 months to 128 months. The mother of patient 6 with obvious skin pigmentation and we confirm her disease by gene sequencing. The other two patients (patient 2 and 4) with suspected positive family history: the maternal cousin of patient 2 had suffered from limb weakness and cutaneous pigmentation, but he refused a further check. The maternal uncle of patient 4 had symptom of ambulation dysfunction, unfortunately we could not identify his disease because of his rejection.

Initial neurological symptoms included stiffness or weakness of the legs in five patients and backache in one left (patient 4). Among them, two patients (patients 1, 4) were initially suspected as hereditary spastic paraplegia because of adolescent onset with spastic paraparesis, and other two patients (patients 2,3) were initially misdiagnosed as subacute combined degeneration due to damage of dorsolateral funiculus and peripheral nerve.

Table 1 Clinical Characteristics of 6 Chinese Patients with Adrenomyeloneuropathy

\begin{tabular}{|c|c|c|c|c|c|c|c|c|c|c|c|}
\hline $\begin{array}{l}\text { Patient } \\
\text { number }\end{array}$ & $\begin{array}{l}\text { Sex/ } \\
\text { Age } \\
\text { (years) }\end{array}$ & $\begin{array}{l}\text { Onset } \\
\text { age } \\
\text { (years) }\end{array}$ & $\begin{array}{l}\text { Spastic } \\
\text { paraparesis }\end{array}$ & $\begin{array}{l}\text { Sensory } \\
\text { deficit }\end{array}$ & $\begin{array}{l}\text { AMN with/ } \\
\text { without cerebral } \\
\text { involvement }\end{array}$ & $\begin{array}{l}\text { Memory / mood } \\
\text { impairment } \\
\text { (onset age) }\end{array}$ & $\begin{array}{l}\text { Adrenal } \\
\text { dysfunction }\end{array}$ & $\begin{array}{l}\text { Sphincter } \\
\text { disturbances }\end{array}$ & $\begin{array}{l}\text { Sexual } \\
\text { dysfunction }\end{array}$ & $\begin{array}{l}\text { Change } \\
\text { of skin / } \\
\text { hair }\end{array}$ & $\begin{array}{l}\text { Family } \\
\text { history }\end{array}$ \\
\hline 1 & $M / 30$ & 21 & + & + & + & - & + & + & + & + & - \\
\hline 2 & M/45 & 38 & + & + & - & - & + & - & + & + & +- \\
\hline 3 & $M / 44$ & 33 & + & + & - & - & + & + & + & + & - \\
\hline 4 & $M / 31$ & 26 & + & - & - & - & + & + & + & + & +- \\
\hline 5 & $M / 40$ & 31 & + & + & - & - & - & + & - & + & - \\
\hline 6 & M/41 & 29 & + & + & + & $+(39)$ & + & + & + & + & - \\
\hline
\end{tabular}

" $M$ " Male," + " positive/with,"-" negative/without, "+-" suspicious 


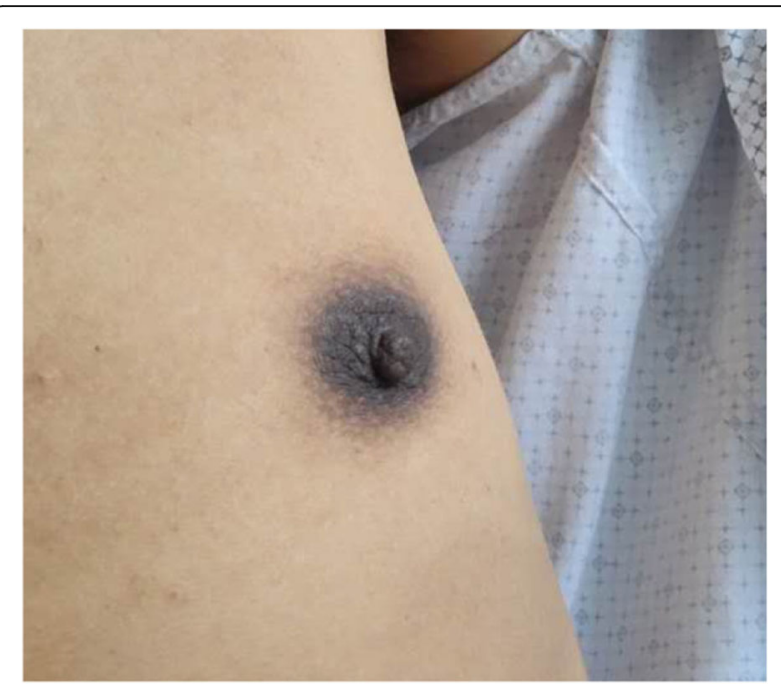

Fig. 1 Hyperpigmentation of the body of patient 2, especially with areolae

Five patients had hyperpigmentation in lips, areolae, gums even the entire body skin (Fig. 1), and the plasma of ACTH concentration of these patients was elevated obviously. After patient 1 and patient 3 had received hydrocortisone therapy regularly, the level of plasma of ACTH returned to normal after 2-4 weeks. Moreover, the symptoms of skin pigmentation and fatigue also significantly improved. Five patients complained decreased libido and erectile dysfunction, but the levels of testosterone were in the normal range. In our cohort, all patients with scanty scalp hair, patient 6 developed male pattern baldness (Fig. 2).

On neurologic examination, all patients presented spasticity and paresis, as well as increased tendon reflexes with Babinski sign. Five patients had urinary disturbance (retention, urgency or incontinence). Patient 6 demonstrated personality change, memory impairment and dysarthria at the age of 39. Although there were lesions in the brain, patient 1 had no obvious personality change or memory impairment. Nerve conduction studies showed abnormalities in 4 of 5 tested patients. Three patients with bilateral peroneal velocity abnormal, the other one with peroneal velocity and amplitude decreased. (The detailed data about NCV can get from the Additional file 1). Somatosensory evoked potential experiments proved that 4 monitored patients had central conduction abnormalities.

\section{Neuroimaging}

All patients underwent brain and spinal MRI testing. As a result, spinal MRI scans showed diffuse cord atrophy in all cases, especially patient 2 and patient 6 (Fig. 3). Interestingly, patient 1 didn't have any obvious mood or memory disturbance until the last follow-up date, but the lesion of splenium of corpus callosum have become more and more visible during the past 6 years (Fig. 4), which indicates that the initial lesions usually relate to the splenium of the corpus callosum and subsequently spread to the adjacent white matter of the parieto-occipital lobe. The brain MRI of patient 6 revealed extensive intracranial lesions, including splenium of corpus callosum, bilateral symmetrical temporo-parietal-occipital white matter, bilateral corticospinal tract, and bilateral dentate nuclei of cerebellar (Fig. 5).

\section{Biochemical}

Table 2 lists the plasma VLCFAs levels of five tested patients. While patient 5 refused to undergo this check after genetic diagnosis. It is revealed that plasma levels of VLCFA, and the proportions of C24:0/C22:0 and C26: 0/C22:0 were elevated in all tested patients. Although patient 1 received treatment with Lorenzo's oil regularly, the plasma levels of $\mathrm{C} 26: 0$, especially the C24:0/C22:0 and $\mathrm{C} 26: 0 / \mathrm{C} 22: 0$ ratios were still above normal range.

\section{Mutational analysis}

To analyze mutational features, five distinct mutations of the ABCD1 sequence were confirmed (Table 3).
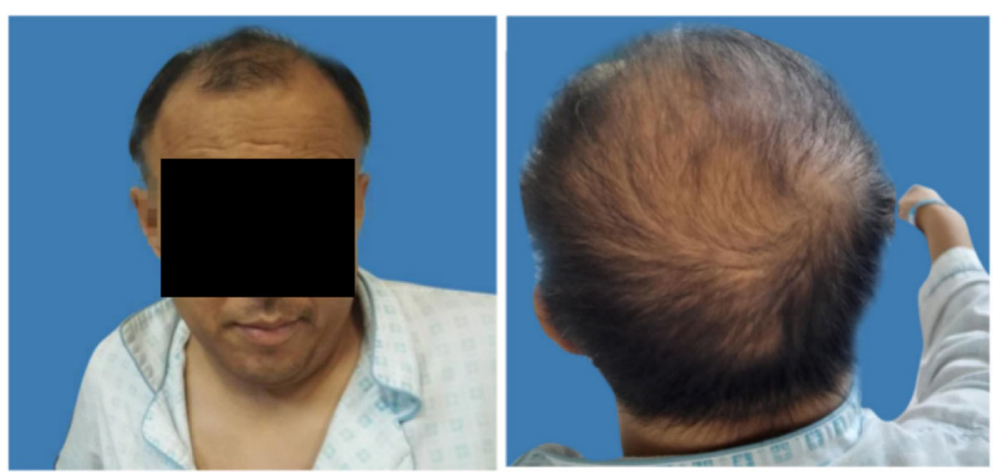

Fig. 2 Patient 6, a 39 years old man, developed male type balding 

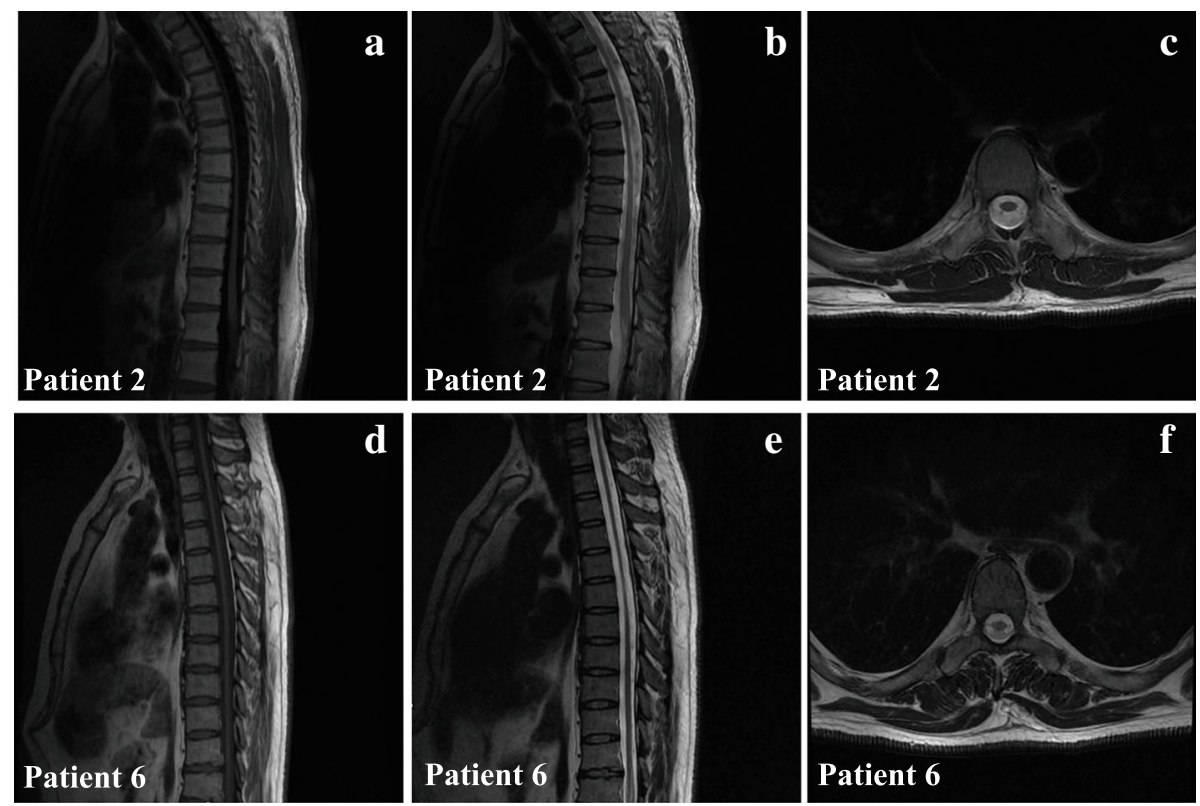

Fig. 3 Spinal MRI scans of patient 2 and patient 6 show diffuse cord atrophy. a Sagittal T1-weighted images of patient 2. b Sagittal T2-weighted images of patient 2. c Axial T2-weighted images of patient 2. d Sagittal T1-weighted images of patient 6. e Sagittal T2-weighted images of patient 6. $\mathbf{f}$ Axial T2-weighted images of patient 6

Among these five different mutations, four are missense, and one is a novel frameshift mutation. As to the missense counterparts, three mutations are identified in the nucleotide binding domains (NBD), and the other one is located in the transmembrane domain. The ALD database (see http://www.x-ald.nl/) actually has disclosed these 4 mutations, which are not only associated with AMN but also with the phenotype of childhood cerebral ALD, adolescent cerebral ALD, adult cerebral ALD, or the asymptomatic patients [12-15]. In this study, one novel frameshift mutation (c.1843dup) was identified in our cohort. As aforementioned, the ABCD1 gene coding for a protein of 745 amino acids (named ALDP), is formed from 10 exons [16]. Here the novel frameshift mutation locates in exon 8, which leads to the protein early terminated at exon 9 (Fig. 6).

\section{Discussion}

Even a series of progress have been accomplished on the $A M N$, a comprehensive exploration with perspective of clinical, neuroimaging, biochemical, and genetic analysis in Chinese AMN patients is still lack.

AMN was proposed due to the involvement of a slowly progressive paraparesis, adrenal insufficiency, hypogonadism combined with peripheral nerves neuropathy and sphincter disturbances [4]. With the discovery and application of VLCFA, AMN was soon found to be a form of phenotypic X-ALD [17, 18]. Nevertheless,
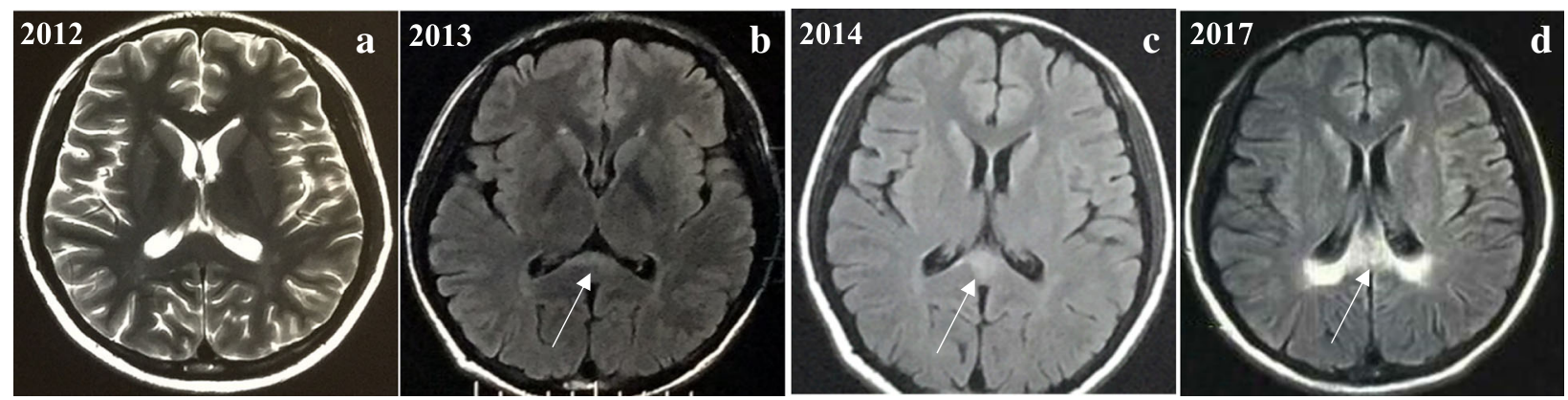

Fig. 4 The evolution of brain MRI scans of patient 1 during last 5 years. a The axial T2-weighted images of brain MRI of 2012 is normal. As indicated by the arrows. b The axial T2-flair images of head MRI of 2013 showed a slight hyperintensity of splenium of corpus callosum. c The axial T2-flair images of head MRI of 2014 showed more abnormal signal of splenium of corpus than in 2013. d T2-flair images of head MRI of 2017 revealed marked hyperintensity of whole splenium of corpus callosum 

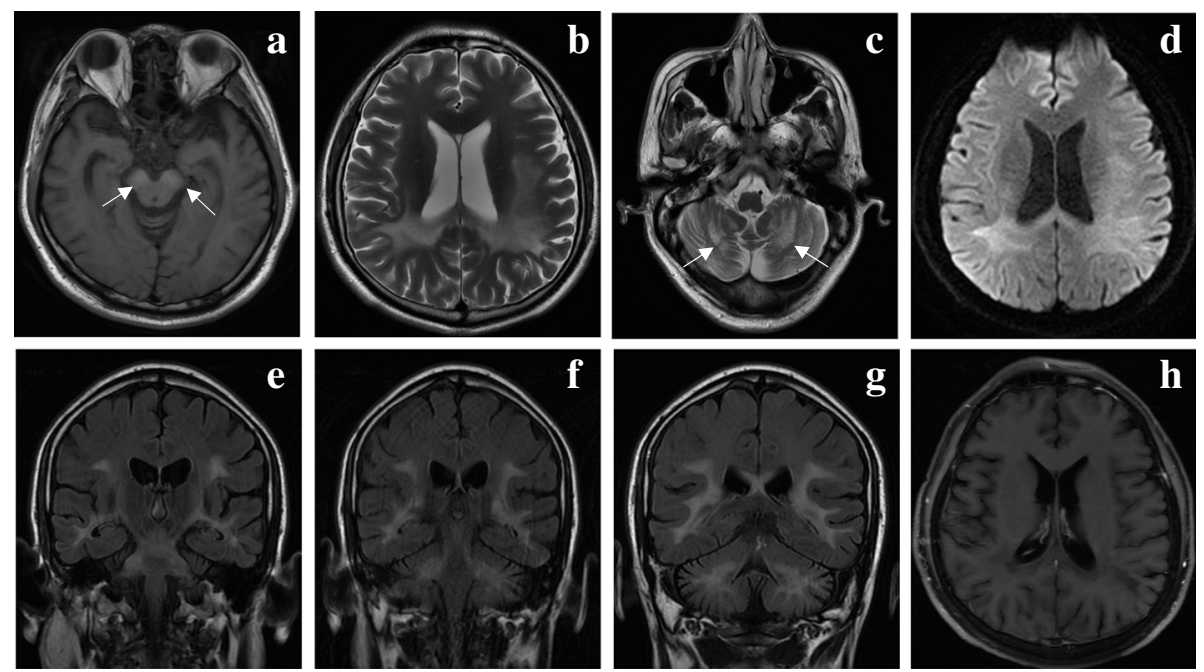

Fig. $5 \mathrm{MRI}$ of the brain images of patient 6 with AMN, shown rapidly deteriorated symptoms with cognitive decline. a The lesion showed increased signal intensity with bilateral corticospinal tract (arrows) on T1-weighted images. b-c The extensive lesions involved the parieto-occipital white matter, splenium of the corpus callosum and bilateral dentate nuclei of cerebellar (arrows) on T2-weighted images. $\mathbf{d}$ The lesion showed slightly increased signal intensity with the parieto-occipital white matter and splenium of the corpus callosum on Diffusion-weighted images. $\mathbf{e}-\mathbf{g}$ The extensive lesions involved the bilateral temporo-parietal-occipital white matter, splenium of the corpus callosum, bilateral corticospinal tract and bilateral dentate nuclei of cerebellar on T2-flair images. $\mathbf{h}$ Axial T1-weighted images after gadolinium administration

neuropathologic study has revealed a more indolent degenerative process, different from the inflammatory cerebral phenotypes [5, 19]. Moreover, reports elucidated that the genotype-phenotype correlation in ALD patients is not evident [20-23]. In our cohort, although they each had the same genotype, the various clinical manifestations of patients $1,2,4$, and 5 were consistent with the AMN phenotype, which is inconsistent with previously reported results [12-15]. These data mean that in addition to primary defect in ABCD1, environmental factors and/or other genes show a strong connection with the development of the disease. This study further confirms that genotype and phenotype may not correlate.

In our cohort, median onset age of neurological symptoms was 29.8 years and ranged $21-38$ years, consisted with previous reports [24, 25]. Five of these patients developed skin pigmentation when they were young. Interestingly, patient 5 had no apparent skin color changes or abnormal plasma ACTH up to the date of follow-up. Moser et al. have suggested that there were $33 \%$ of AMN patients with normal adrenal function at all points (normal cortisol response to ACTH and normal baseline ACTH levels). Nevertheless, it's likely that this percentage was underestimated, which may be attributed to part of neurologists who didn't have sufficient knowledge to interpret the result as adrenal function is normal [24]. Therefore, we think that "myeloneuropathy-only" is an important phenotype of ALD. There were two of six patients (patient 1 and 6,) with cerebral involvement (33\%), higher than that (about $19 \%)$ reported by van Geel et al., but lower than that (about 63\%) from de Beer et al. [10, 26]. It is noteworthy that the patient's mental state, walking ability and verbal

Table 2 Plasma VLCFAs levels of five Chinese patients with Adrenomyeloneuropathy

\begin{tabular}{|c|c|c|c|c|c|}
\hline Patient & $\begin{array}{l}\text { C22:0 (25.49- } \\
74.51 \mu \mathrm{mol} / \mathrm{L})\end{array}$ & $\begin{array}{l}\text { C24:0 (20.85- } \\
61.50 \mu \mathrm{mol} / \mathrm{L})\end{array}$ & $\begin{array}{l}\text { C26:0 (0.22- } \\
0.74 \mu \mathrm{mol} / \mathrm{L})\end{array}$ & $\begin{array}{l}\text { C26:0/C22:0 (0.004- } \\
0.016)\end{array}$ & $\begin{array}{l}\text { C24:0/C22:0 (0.69- } \\
0.96)\end{array}$ \\
\hline $\begin{array}{l}1 \text { (before treated with } \\
\text { Lorenzo's oil) }\end{array}$ & 42.5 & 62.3 & $1.12 \uparrow$ & $0.09 \uparrow$ & $1.63 \uparrow$ \\
\hline $\begin{array}{l}1 \text { (after treated with Lorenzo's } \\
\text { oil) }\end{array}$ & $10.1 \downarrow$ & $14.8 \downarrow$ & $0.76 \uparrow$ & $0.16 \uparrow$ & $1.56 \uparrow$ \\
\hline 2 & 49.1 & $102.4 \uparrow$ & $2.81 \uparrow$ & $0.057 \uparrow$ & $2.09 \uparrow$ \\
\hline 3 & 40.8 & 66.8 & $1.21 \uparrow$ & $0.070 \uparrow$ & $2.00 \uparrow$ \\
\hline 4 & 30.2 & 58.4 & $1.48 \uparrow$ & $0.049 \uparrow$ & $1.93 \uparrow$ \\
\hline 6 & 38.0 & 70.0 & $2.34 \uparrow$ & $0.062 \uparrow$ & $1.84 \uparrow$ \\
\hline
\end{tabular}

VLCFAs very long chain fatty acids 
Table 3 The Mutational Analysis of five Chinese patients with Adrenomyeloneuropathy

\begin{tabular}{lllllll}
\hline Patient number & Exon & Nucleotide change & Allele & Protein localization & Type & Reference \\
\hline 1 & 8 & c.1849C > T & p. Arg617Cys & NBD & Missense & Kumar et al., 2010 [12] \\
2 & 1 & c.346G > A & p. Gly116Arg & TMD & Missense & Feigenbaum et al.,1996 [13] \\
4 & 8 & c.1817C > T & p. Ser606Leu & NBD & Missense & Fanen et al.,1994 [14] \\
5 & 3 & c.1166G > A & p. Arg389His & TMD to NBD & Missense & Kok et al.,1995 [15] \\
6 & 8 & c.1843dup & p. Met615fs & NBD & Frameshift & Novel \\
\hline
\end{tabular}

$T M D$ transmembrane domains, NBD nucleotide-binding domains. ${ }^{a}$ :termination codon

ability showed significant deterioration about half a year after the divorce. According to previous reports, head trauma may be a possible environmental trigger [27-29] but other modifiers (both genetic and environmental) have not yet been identified. We boldly guess that emotional trauma (such as divorce) may be an enviromental factor, which intiates or aggravates cerebral disease.

MRI is an important tool for diagnosis and detecting the evolution of the disease. As displayed in Fig. 4, patient 1's head MRI evolution indicated that intracranial lesions originate from the splenium of the corpus callosum and then increasingly extend to the periventricular and occipital-parietal white matter. Interestingly, patient 1 didn't show any obvious mood, memory disturbance or other psychiatric symptoms, which implies that white matter lesions on MRI may preact symptoms. It is consistent with the findings of van der Knaap et al. [30, 31]. Therefore, regular head MRI evaluation is very important for patients with AMN or ALD [32,33]. The brain
MRI of patient 6 showed extensive lesions, including splenium of corpus callosum, bilateral symmetrical temporo-parietal-occipital white matter, bilateral corticospinal tract, and bilateral dentate nuclei of cerebellar, some lesions confluent. The lesions were compatible with previous results of Loes et al. [34, 35]. Although no enhancement of demyelinating lesions of patient 6's head MRI were observed, diffusion-weighted images showed slightly increased signal intensity with the splenium of the corpus callosum as well as parieto-occipital white matter. Meanwhile, the patient experienced a considerable decline in cognitive function. It demonstrates that he develops into the rapidly progressive neuroinflammatory stage and his condition will deteriorate progressively.

Although patient 1 received Lorenzo's oil treatment regularly, plasma C26:0 levels were nearly normal, intracranial lesions are still developing. It is compatible with previous studies [36, 37].

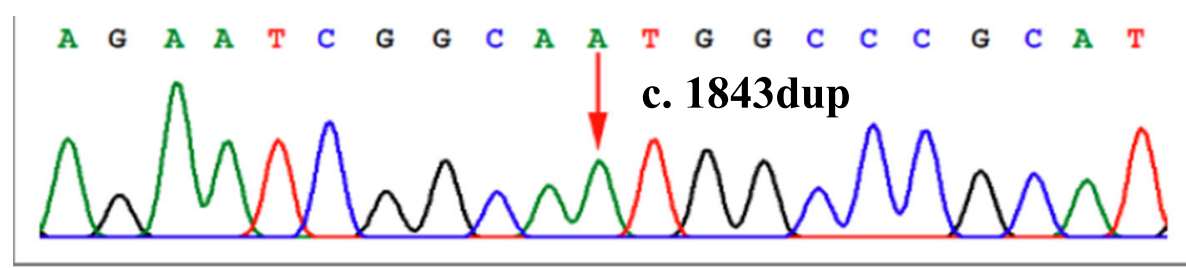

$\mathbf{a}$

\section{Protein predicted from variant coding sequence}

1 MPVLSRPRPW RGNTLKRTAV LLALAAYGAH KVYPLVRQCL APARGLQAPA GEPTQEASGV

61 AAAKAGMNRV FLQRLLWLLR LLFPRVLCRE TGLLALHSAA LVSRTFLSVY VARLDGRLAR

121 CIVRKDPRAF GWQLLQWLLI ALPATFVNSA IRYLEGQLAL SFRSRLVAHA YRLYFSQQTY

181 YRVSNMDGRL RNPDQSLTED WAFAASVAH LYSNLTKPLL DVAVTSYTLL RAARSRGAGT

241 AWPSAIAGLV VFLTANVLRA FSPKFGELVA EEARRKGELR YMHSRWVANS EEIAFYGGHE

301 VELALLQRSY QDLASQINLI LLERLWYVML EQFLMKYWWS ASGLLMVAVP IITATGYSES

361 DAEAVKKAAL EKKEEELVSE RTEAFTIARN LLTAAADAIE RIMSSYKEVT ELAGYTARVH

421 EMFQVFEDVQ RCHFKRPREL EDAQAGSGTI GRSGVRVEGP LKIRGQVVDV EQGIICENIP

481 IVTPSGEWW ASLNIRVEEG MHLLITGPNG CGKSSLFRIL GGLWPTYGGV LYKPPPQRMF

541 YIPQRPYMSV GSLRDQVIYP DSVEDMQRKG YSEQDLEAIL DWHLHHILQ REGGWEAMCD

601 WKDVLSGGEK QRIGNGPHVL. PQAQVRPPG*

Fig. 6 a The sequencing profiles of the novel mutation of patient 6 . $\mathbf{b}$ The novel frameshift mutation caused the changing of the 615 th amino acid located in exon 8, which leaded to the protein early terminated at exon 9 
In our cohort, we found a novel frameshift mutations in patient 6 (Fig. 6). The Sanger sequencing results of $\mathrm{ABCD} 1$ gene in the family demonstrated a nucleotide insertion mutation A at cDNA nucleotide 1843(c.1843dup) which was observed in the patient's mother. In addition, this frameshift mutation was not reported in previous studies. Combining with the clinical, imaging and biochemical characteristics of the patient, we recommend to define the mutation as Pathogenic.

\section{Conclusions}

In conclusion, this study aims at illuminating basic features from the clinical, neuroimaging, biochemical, and genetic aspects of some Chinese AMN patients. A de novo mutation stemmed from ABCD1 gene was identified. Plasma VLCFA and ABCD1 gene analysis should be tested for the patients who present with Addison disease and spastic paraparesis, especially encountering with 'myeloneuropathy-only'. It is also critical to diagnose AMN rapidly owing to the insistent demands of genetic counseling and applications of targeted and specific treatment options.

\section{Additional file}

Additional file 1: The detailed data about NCV of patients. (DOCX 19 kb)

\begin{abstract}
Abbreviations
ABCD1: ATP binding cassette subfamily D member 1;

ACTH: Adrenocorticotropic hormone; ALD: Adrenoleukodystrophy; AMN: Adrenomyeloneuropathy; MRI: Magnetic Resonance Imaging; OMIM: Online Mendelian Inheritance in Man; PLA: Chinese People's Liberation Army; VLCFA: Very long chain fatty acids; X-ALD: X-linked adrenoleukodystrophy
\end{abstract}

\section{Acknowledgments}

Not applicable.

\section{Authors' contributions}

$\mathrm{DHH}$ conceived and designed the research. $\mathrm{J}$ and HFW acquired, analyzed and interpreted the data. ZZH guided in the charting process. JT ensured that the patient's MRI findings were accurately characterized. JL draft the manuscript. DHH, XQW, JL, HFW, ZZH and JT made critical revisions of the manuscript. All authors approved the final manuscript.

\section{Funding}

This work was financially supported by a grant from the Nursery Fund of People's Liberation Army General Hospital (grant No. 15KMM01). The funding body had no role or interference in the design of the study, collection, analysis, interpretation of data and in writing the manuscript.

\section{Availability of data and materials}

All data generated or analyzed during this study are included in this published article.

\section{Ethics approval and consent to participate}

All patients or their lineal relatives signed written informed consent. For participants who were unable to provide informed consent due to medical condition or severe dementia, participation was based on proxy consent given by family proxies. The study protocol has been approved by the Institutional Review Board of Chinese PLA General Hospital. The reference numbers for the ethical approval is S2016-021-01.

\section{Consent for publication}

Written informed consent was obtained from all patients or their lineal relatives for publication of this article and any accompanying images. Due to intelligence deficits, the informed consent was signed by family proxies.

\section{Competing interests}

The authors declare that they have no competing interests.

\section{Author details}

'Department of Neurology, Chinese PLA General Hospital, Fuxing Road 28, Haidian District, Beijing 100853, People's Republic of China. ${ }^{2}$ Department of Radiology, Chinese PLA General Hospital, Beijing 100853, People's Republic of China.

Received: 25 November 2018 Accepted: 27 August 2019

Published online: 16 September 2019

\section{References}

1. Moser HW. Adrenoleukodystrophy: phenotype, genetics, pathogenesis and therapy. Brain. 1997;120(8):1485-508.

2. van Geel BM, Assies J, Wanders RJ, Barth PG. X linked adrenoleukodystrophy: clinical presentation, diagnosis, and therapy. J Neurol Neurosurg Psychiatry. 1997;63(1):4-14

3. Budka H, Sluga E, Heiss WD. Spastic paraplegia associated with Addison's disease: adult variant of adreno-leukodystrophy. J Neurol. 1976;213(3):237-50.

4. Griffin JW, Goren E, Schaumburg H, Engel WK, Loriaux L. Adrenomyeloneuropathy: a probable variant of adrenoleukodystrophy. I. Clinical and endocrinologic aspects. Neurology. 1977;27(12):1107-13.

5. Powers JM, DeCiero DP, Ito M, Moser AB, Moser HW. Adrenomyeloneuropathy: a neuropathologic review featuring its noninflammatory myelopathy. J Neuropathol Exp Neurol. 2000;59(2):89-102.

6. Powers JM, DeCiero DP, Cox C, et al. The dorsal root ganglia in adrenomyeloneuropathy: neuronal atrophy and abnormal mitochondria. J Neuropathol Exp Neurol. 2001;60(5):493-501.

7. Dubey P, Fatemi A, Barker PB, et al. Spectroscopic evidence of cerebral axonopathy in patients with "pure" adrenomyeloneuropathy. Neurology. 2005;64(2):304-10

8. van Geel BM, Koelman JH, Barth PG, Ongerboer de Visser BW. Peripheral nerve abnormalities in adrenomyeloneuropathy: a clinical and electrodiagnostic study. Neurology. 1996:46(1):112-8.

9. Chaudhry V, Moser HW, Cornblath DR. Nerve conduction studies in adrenomyeloneuropathy. J Neurol Neurosurg Psychiatry. 1996;61(2):181-5.

10. van Geel BM, Bezman L, Loes DJ, Moser HW, Raymond GV. Evolution of phenotypes in adult male patients with X-linked adrenoleukodystrophy. Ann Neurol. 2001;49(2):186-94.

11. Kemp S, Berger J, Aubourg P. X-linked adrenoleukodystrophy: clinical, metabolic, genetic and pathophysiological aspects. Biochim Biophys Acta. 2012;1822(9):1465-74.

12. Kumar N, Taneja KK, Kumar A, et al. Novel mutation in ATP-binding domain of ABCD1 gene in adrenoleukodystrophy. J Genet. 2010;89(4):473-7.

13. Feigenbaum V, Lombard-Platet G, Guidoux S, Sarde CO, Mandel JL, Aubourg $P$. Mutational and protein analysis of patients and heterozygous women with X-linked adrenoleukodystrophy. Am J Hum Genet. 1996;58(6):1135-44.

14. Fanen P, Guidoux S, Sarde CO, Mandel JL, Goossens M, Aubourg P. Identification of mutations in the putative ATP-binding domain of the adrenoleukodystrophy gene. J Clin Invest. 1994;94(2):516-20.

15. Kok F, Neumann S, Sarde CO, et al. Mutational analysis of patients with X-linked adrenoleukodystrophy. Hum Mutat. 1995:6(2):104-15.

16. Mosser J, Douar AM, Sarde CO, et al. Putative X-linked adrenoleukodystrophy gene shares unexpected homology with $A B C$ transporters. Nature. 1993;361(6414):726-30.

17. Moser HW, Moser AB, Frayer KK, et al. Adrenoleukodystrophy: increased plasma content of saturated very long chain fatty acids. Neurology. 1981;31(10):1241-9.

18. Huffnagel IC, van de Beek M-C, Showers AL, et al. Comparison of C26: 0carnitine and C26: 0-lysophosphatidylcholine as diagnostic markers in dried blood spots from newborns and patients with adrenoleukodystrophy. Mol Genet Metab. 2017;122(4):209-15.

19. Schaumburg HH, Powers JM, Raine CS, et al. Adrenomyeloneuropathy: a probable variant of adrenoleukodystrophy. II. General pathologic, neuropathologic, and biochemical aspects. Neurology. 1977;27(12):1114-9. 
20. Kemp S, Ligtenberg MJ, van Geel BM, et al. Identification of a two base pair deletion in five unrelated families with adrenoleukodystrophy: a possible hot spot for mutations. Biochem Biophys Res Commun. 1994;202(2):647-53.

21. Smith KD, Kemp S, Braiterman LT, et al. X-linked adrenoleukodystrophy: genes, mutations, and phenotypes. Neurochem Res. 1999;24(4):521-35.

22. Berger J, Molzer B, Fae I, Bernheimer H. X-linked adrenoleukodystrophy (ALD): a novel mutation of the ALD gene in 6 members of a family presenting with 5 different phenotypes. Biochem Biophys Res Commun. 1994;205(3):1638-43.

23. Korenke GC, Fuchs S, Krasemann E, et al. Cerebral adrenoleukodystrophy (ALD) in only one of monozygotic twins with an identical ALD genotype. Ann Neurol. 1996;40(2):254-7.

24. Moser HW, Moser AB, Naidu S, Bergin A. Clinical aspects of adrenoleukodystrophy and adrenomyeloneuropathy. Dev Neurosci. 1991; 13(4-5):254-61.

25. Wang AG. X-Linked Adrenoleukodystrophy[M]//Emergency Neuroophthalmology. Singapore: Springer; 2018. p. 137-41.

26. de Beer M, Engelen M, van Geel BM. Frequent occurrence of cerebral demyelination in adrenomyeloneuropathy. Neurology. 2014;83(24):2227-31.

27. Raymond GV, Seidman R, Monteith TS, et al. Head trauma can initiate the onset of adreno-leukodystrophy. J Neurol Sci. 2010;290(1-2):70-4.

28. Bouquet F, Dehais C, Sanson M, Lubetzki C, Louapre C. Dramatic worsening of adult-onset $X$-linked adrenoleukodystrophy after head trauma. Neurology. 2015;85(22):1991-3.

29. Kemp S, Huffnagel IC, Linthorst GE, Wanders RJ, Engelen M. Adrenoleukodystrophy - neuroendocrine pathogenesis and redefinition of natural history. Nat Rev Endocrinol. 2016;12(10):606-15.

30. van der Knaap MS VJ. X-linked adrenoleukodystrophy. In Magnetic Resonance of Myelination and Myelin Disorders. 3rd edition. Edited by Heilmann U. Berlin-Heidelberg-New York. Springer 2005: 176-90.

31. Manara R, Burlina AP. Neuroimaging of inherited metabolic diseases of adulthood[M]//Neurometabolic hereditary diseases of adults. Cham: Springer; 2018. p. 43-65.

32. Engelen $\mathrm{M}$, Kemp $\mathrm{S}$, de Visser $\mathrm{M}$, et al. X-linked adrenoleukodystrophy (X-ALD): clinical presentation and guidelines for diagnosis, follow-up and management. Orphanet J Rare Dis. 2012;7:51.

33. Bladowska J, Kulej D, Biel A, et al. The role of MR imaging in the assessment of clinical outcomes in children with X-linked adrenoleukodystrophy after allogeneic haematopoietic stem cell transplantation. Pol J Radiol. 2015:80:181.

34. Loes DJ, Fatemi A, Melhem ER, et al. Analysis of MRI patterns aids prediction of progression in X-linked adrenoleukodystrophy. Neurology. 2003;61(3):369-74.

35. Moser $A B$, Fatemi $A$. Newborn screening and emerging therapies for $X$ linked Adrenoleukodystrophy[]]. JAMA Neurol. 2018;75(10):1175-6.

36. van Geel BM, Assies J, Haverkort EB, et al. Progression of abnormalities in adrenomyeloneuropathy and neurologically asymptomatic X-linked adrenoleukodystrophy despite treatment with "Lorenzo's oil". J Neurol Neurosurg Psychiatry. 1999;67(3):290-9.

37. Morita M, Honda A, Kobayashi A, et al. Effect of Lorenzo's oil on hepatic gene expression and the serum fatty acid level in abcd1-deficient mice. JIMD Rep. 2018:38:67-74.

\section{Publisher's Note}

Springer Nature remains neutral with regard to jurisdictional claims in published maps and institutional affiliations.

Ready to submit your research? Choose BMC and benefit from:

- fast, convenient online submission

- thorough peer review by experienced researchers in your field

- rapid publication on acceptance

- support for research data, including large and complex data types

- gold Open Access which fosters wider collaboration and increased citations

- maximum visibility for your research: over $100 \mathrm{M}$ website views per year

At $\mathrm{BMC}$, research is always in progress.

Learn more biomedcentral.com/submissions 